\title{
O PAPEL DA EDUCAÇÃO NO HOSPITAL: UMA REFLEXÃO COM BASE NOS ESTUDOS DE WALLON E VIGOTSKI
}

\author{
Rejane de Souza Fontes* \\ Vera Maria Ramos de Vasconcellos ${ }^{* *}$
}

\begin{abstract}
RESUMO: A educação no hospital ainda é um tema novo para a academia e possui poucos estudos nesta área. Com o objetivo de contribuir para o debate, o texto apresenta, através da análise de cenas de um atendimento pedagógico em hospital, possibilidades de interlocução entre a educação e a saúde. Com base nos estudos de Wallon e Vigotski, o artigo discute cenas de interação entre quatro crianças, os diferentes papéis que a educação pode desempenhar no contexto hospitalar. A aprendizagem como elemento propulsor do desenvolvimento ganha novos contornos numa enfermaria pediátrica. Além de resgatar a auto-estima da criança, o ato de aprender gera conhecimentos que contribuem para refletir sobre sua doença e compreender as causas que the trazem desconforto emocional, diminuindo a tensão de uma hospitalização. Assim, ao proporcionar momentos de construção, expressão e reelaboração de pensamentos, a educação tem um importante papel a desempenhar no resgate da saúde da criança hospitalizada.
\end{abstract}

Palavras-chave: Educação. Saúde. Interação. Emoção. Pensamento.

THE ROLE OF EDUCATION IN HOSPITALS:

A REFLECTION BASED ON WALLON AND VYGOTSKY'S STUDIES

ABSTRACT: Education in hospitals is still a new subject in academic terms, and not many studies have been carried out in this area. With the goal of adding to the debate, this paper presents

\footnotetext{
* Doutora em Educação, supervisora educacional da Prefeitura de São Gonçalo (RJ) e tutora de Educação a Distância do CEDERJ. E-mail: rejane_fontes@yahoo.com.br

** Professora titular do Programa de Pós-Graduação em Educação (Proped) e da Faculdade de Educação da UERJ e coordenadora do Núcleo de Estudos da Infância: Pesquisa \& Extensão (NEI:P\&E/UERJ). E-mail:vmrv@opelink.com.br
} 
possibilities of interrelation between education and health, through an analysis of images of a pedagogic approach to patients in hospitals. Drawing on Wallon and Vygotsky's studies, the article presents an analysis of interaction between four children and a discussion on the different roles that can be played by education within hospitals. Learning as an element to trigger development acquires new elements when it happens within a children's ward in a hospital. Not only does it bring back children's self-esteem; it also brings knowledge that helps children think about their illnesses and understand the reasons why these illnesses bring them emotional unease, thus reducing the level of tension commonly experienced in hospitals and providing them with moments of thought construction, expression and restructuring. This is how education has been playing an important role in the recovery of hospitalized children's health.

Key words: Education. Health. Interaction. Emotion. Thought.

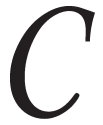

ada vez mais o hospital tem se firmado como um campo de prática e conhecimento para profissionais e estudiosos da área de educação. Todavia, o número de publicações acerca do tema ainda é restrito. Isso mostra a fragilidade teórica da área, que não possui um corpus de conhecimento consolidado e indica a necessidade de mais pesquisas que enriqueçam o debate.

$\mathrm{Na}$ tentativa de contribuir para este enriquecimento, o presente artigo se propõe a analisar, com base nos estudos de Henry Wallon e Lev Vigotski, qual a contribuição da educação para o resgate da saúde de crianças hospitalizadas. O fio condutor de nossa análise será uma situação de interação de quatro crianças internadas na enfermaria pediátrica do Hospital Universitário Antônio Pedro (HUAP), em Niterói (RJ).

Ao lado das interações e brincadeiras infantis, o desenho é uma atividade comum na enfermaria pediátrica. Ele assume um canal privilegiado de expressão de sentimentos e foi por meio dele que estabelecemos nosso primeiro contato com esse grupo de crianças. Através do desenho, como já evidenciado por Taam (2000) e Fontes (2003), as crianças exprimem suas angústias, seus medos, suas decepçóes e suas alegrias.

Segundo Wallon (1975), o desenho, como forma de expressão preferida das crianças, é revelador de pensamentos porque também é uma forma de linguagem. Pelo desenho a criança revela o conhecimento conceitual que tem da realidade e os aspectos mais significativos de sua experiência. 
Para este autor, a vocação social da criança implica uma troca incessante com o meio em que vive. Embora médico de formação, Wallon tomou os rumos da Psicologia e da Educação, problematizando o homem concreto, entendendo-o na sua totalidade corpo-mente ou na perspectiva posteriormente denominada de walloniana, que integra a inteligência, a emoção e o movimento.

No diálogo com Wallon e Vigotski compreendemos que o indivíduo, utilizando sua inteligência, age sobre o meio, transformando-o e sendo por ele transformado. Para Wallon (1941), não há limites para a aquisição de conhecimentos pelo homem. É a cultura e a linguagem que fornecem ao pensamento os instrumentos para sua evolução. O simples amadurecimento do sistema nervoso não garante o desenvolvimento de habilidades intelectuais mais complexas.

Wallon entende que a criança é um ser geneticamente social, ou seja, nasce num meio envolvente do qual depende inteiramente para a satisfação de seus desconfortos e necessidades, sendo um ser biológico que nasce já social e membro de um grupo com cultura e linguagem próprias. (Vasconcellos, 2002, p. 46)

Para ele, o organismo é a primeira condição do pensamento, afinal, toda função psíquica supõe um equipamento orgânico. Todavia, o próprio autor nos adverte que isso não é suficiente, uma vez que o objeto do pensamento vem do meio no qual o indivíduo encontra-se inserido.

Confirmando tais idéias, Vigotski (2000a) defende que o indivíduo não existe isolado, ele se constrói e constrói o outro na interação. Por isso, o desenvolvimento humano é visto como um empreendimento conjunto e não individual. A aquisição de conhecimento é um processo construído pelo indivíduo durante toda sua vida, não estando pronto ao nascer, nem sendo adquirido passivamente graças às açóes do meio.

Numa enfermaria pediátrica, o desenvolvimento de crianças não é diferente. Mesmo doente, elas continuam interagindo, apropriando-se das informações disponíveis no meio e transformando-as em conhecimento. O papel da educação é, então, estimular essa construção, possibilitando a cada criança uma reflexão sobre o meio, sua doença, seus sentimentos e ajudando-as a entender o que acontece com elas e ao seu redor. Dessa forma, a educação no hospital pode fortalecer a auto-estima das crianças para o enfrentamento da situação de hospitalização, como veremos nos episódios transcritos a seguir. 
Vale lembrar que todos os episódios compõem uma única cena, gravada e transcrita textualmente pela primeira autora, enquanto interagia com as crianças na sala de recreação. ${ }^{1}$ A apresentação em diversos episódios foi uma alternativa encontrada para facilitar sua análise.

\section{Cena I: compartilhando conhecimentos...}

A cena a seguir apresenta um grupo heterogêneo de quatro crianças ${ }^{2}$ entre 5 e 16 anos, reunidas na sala de recreação da enfermaria pediátrica do HUAP para desenvolver atividades pedagógicas. Para facilitar a visualização das cenas, usaremos a seguinte legenda, a fim de identificar as falas dos personagens envolvidos: (P) Professora-pesquisadora; (J) Jéssica ${ }^{3}$ (menina, 9 anos); (C) Camila (menina, 7 anos); (S) Suzan (adolescente, 16 anos); (L) Léo (menino, 5 anos) e (E) Enfermeira.

(P) Vem aqui. Vem cá. Senta aqui Suzan. Vocês conhecem a Suzan? ${ }^{4}$ Todo mundo aqui se conhece? Vocês se conhecem?

(J) Esta é Suzan. Esta é a Camila. Esta d'aqui é a vovó de Camila. O pai de Daniel.

(P) Hi, apresentou todo mundo! Gostei!

(C) E você é a tia!

(P) Eu sou a tia? Por que que eu sou a tia?

(C) Ué, porque você é!

(P) Quem está aqui pela primeira vez? Primeira vez que vem ao hospital, que você fica internado?

(J) A minha é a primeira vez. Camila é a segunda vez.

(P) É a segunda vez a sua, não é Camila?

(P) para (L): E a sua vez, é a primeira que você está no hospital? É? Todo mundo sabe por que está aqui?

(J) Eu sei. Porque eu tenho pneumonia.

(P) É? E você Camila? Você sabe por que que está aqui?

(C) Pneumonia.

(P) Pneumonia também? A outra vez também foi?

(C) (Reticente e com olhar distante responde...) Foi... 
(P) Foi. E você Suzan?

(S) Anorexia.

(C) O que?

(P) Anorexia. Todo mundo sabe o que é anorexia?5

(J) É uma gente que não come.

(P) É isso, Suzan? É verdade?

(S) É.

(P) Vocês moram onde? Você mora onde, Léo?

(L) Itaboraí.

(P) Itaboraí. Nossa! E você, Camila?

(C) Fonseca.

(P) Você mora aqui perto, não é? E você, Jéssica?

(J) Rio de Janeiro.

(P) Rio de Janeiro? Na cidade maravilhosa? É?

(J) Mas não é depois da baía, não!

(P) Você mora onde?

(J) São Gonçalo, Rio de Janeiro.

(P) Ah... São Gonçalo... São Gonçalo é um município do estado do Rio de Janeiro.

(J) Pois é, eu sei.

(P) Você mora onde em São Gonçalo?

(J) Portão do Rosa.

(P) Perto do Centro, não é?

(J) Você conhece o Centro de Ensino Amor Perfeito? ${ }^{6}$

(P) Já ouvi falar, mas nunca estive lá. Você estuda lá?

(J) É...

À medida que as atividades aconteciam, as interações sociais tendiam a se ampliar, tornando-se mais complexas. As crianças passavam a se conhecer e a se solidarizar com os companheiros mais constantes. As interações deflagradas pelas atividades em grupo auxiliavam cada 
criança a compreender melhor o que estava acontecendo com ela e ao seu redor, possibilitando-lhe dominar o novo ambiente com mais segurança. $\mathrm{O}$ colorido e os brinquedos da sala de recreação, onde as atividades aconteciam, pareciam exercer um fascínio sobre elas e seus acompanhantes, pois todos gostavam de se reunir ali.

A atividade começou com uma apresentação coletiva. Embora a pesquisadora não tivesse se apresentado como professora, Camila logo a identificou como a tia (leia-se professora) naquele grupo de crianças. Esta é uma manifestação que resgata o conceito de escola, uma vez que as atividades desenvolvidas eram na sala de recreação.

Conhecer o significado de suas doenças e também das doenças das demais crianças hospitalizadas pode ajudar não somente a esclarecer sobre as forma de tratamento e profilaxia (se houver), como também contribui para desenvolver uma estabilidade emocional, a partir do momento em que a criança ou o adolescente vai tomando consciência do que está ocorrendo, entendendo seus limites e possibilidades. Obter informações sobre uma realidade imediata que os atinge concretamente amplia seu arcabouço de conhecimento sobre o mundo. É nesse sentido que o desenvolvimento de atividades educativas em hospital contribui para a saúde da criança que ali se encontra. Os aspectos do conhecimento desta realidade são defendidos por Taam (2000) e Fontes (2003, 2005a, 2005b).

Wallon nos lembra que se a atividade for do interesse da criança, ou seja, aquela voltada para sua realidade próxima e diretamente relacionada à constituição de sua subjetividade, as chances de motivar a participação infantil serão maiores. De acordo com esta idéia, a Pedagogia Hospitalar parece ser o princípio fundamental de todo o trabalho educativo a ser desenvolvido junto às crianças hospitalizadas. A aprendizagem defendida como elemento propulsor do desenvolvimento ganha novos contornos numa atividade pedagógica em hospital.

Quando Jéssica diz que anorexia é uma gente que não come, ela está tentando articular seus conceitos espontâneos ao conceito científico ligado à palavra anorexia. Para Vigotski (2000b), os conceitos espontâneos são construídos a partir da experiência cotidiana, enquanto os conceitos científicos são sistematizados pela educação escolar. No caso de Jéssica, e das demais crianças que com ela interagiam naquele momento, a aquisição do conceito científico se deu no hospital. 
A aquisição de conceitos modifica o processo de percepção da realidade. A formação dos primeiros conceitos relacionados à doença da criança hospitalizada se dá comumente a partir do discurso médico dirigido ao seu acompanhante ou a outro membro da equipe de saúde; raramente é dirigido à própria criança, numa linguagem em que ela possa compreender.

Talvez uma das maiores contribuições de Vigotski para a educação tenha sido seu esforço em tentar compreender a relação entre o aprendizado e o desenvolvimento em crianças em idade escolar. Para ele, aprendizado e desenvolvimento estão interrelacionados desde o primeiro dia de vida. Sendo assim, o aprendizado começava muito antes da criança ir para a escola. Junto a esta discussão, Vigotski introduziu um novo conceito que pareceu revolucionar o nível das discussões empreendidas até então: o de zona de desenvolvimento proximal (ZDP).

Cena II: a zona de desenvolvimento proximal no espaço hospitalar...

Enquanto procurava as tintas, continuei conversando com as crianças.

(P) Léo, você tem quantos anos?

(L) Cinco.

(P) Cinco? Você está na escola?

Léo diz um não com um movimento da cabeça.

(P) Não?

Léo secamente me responde que não.

(P) Camila fez quantos, sete ou oito?

(C) Sete.

(L) Sete? Vige Maria!

(L) Tá estudando?

(C) Claro!

(L) Me dá a cola, tia.

(P) Léo, ou a cola, ou a tinta. Tá bom? Porque ela fez assim (referindo-se à Camila). Ela primeiro usou a tinta. Agora ela está usando a cola. O que você vai fazer primeiro? 
(L) Ela pegou qual?

(P) Ela pegou a tinta daqui. E agora, ela está pegando a cola daí.

(L) Ela pegou a tinta primeiro?

(P) Foi...

(L) Eu vou pegar a tinta. E depois você me dá a cola.

Jéssica, então, mostrou o seu desenho.

(P) Ih, que garota esperta... Mas, olha só, o Brasil fez dois gols ou dois gol?

(J) Dois gol.

(P) Dois gol? Não é dois gols, não?

Jéssica soletrando e apontando com o dedo sua escrita, não conseguia perceber seu equívoco, que lhe foi apontado por Camila.

(C) Dois gols.

(P) Isso. Jóia. Muito bom Camila.

A temática escola apareceu algumas vezes ao longo das interações. Se estar na escola parecia ser uma referência natural para as crianças hospitalizadas, para Léo estar fora dela lhe causava embaraço e estranheza. Este fato pode ser observado na pergunta que Léo fez a Camila: Tá estudando? Ele reproduzia a pergunta que a professora-pesquisadora lhe havia feito momentos antes. A resposta de Camila de estar freqüentando uma escola soou como algo absolutamente natural: Claro!

Léo nunca fora à escola. Talvez, por isso, não compreendesse alguns códigos desse universo social. Percebemos em Léo, devido a sua inexperiência escolar, a ausência de algumas habilidades já presentes em crianças de sua idade que estão em escola de educação infantil; ou, ain$\mathrm{da}$, o desejo de trabalhar com todos os materiais ao mesmo tempo, quando as demais crianças já conseguiam estabelecer uma ordem de uso para os materiais disponíveis. Sua convivência com Camila, que ele elegeu como parceira privilegiada neste espaço de interação, tendeu a provocar modificações em seu comportamento. Ao interagir com Camila, que transportava para o ambiente hospitalar sua vivência de escola, Léo parecia apreender novas experiências relacionadas à cultura escolar.

Para Vigotski (2000a), o convívio com sujeitos mais experientes da cultura tende a favorecer novas aprendizagens que estimulam o desenvolvimento cognitivo da criança. Em seus estudos, Vigotski 
se propôs a explicar a relação dinâmica entre o aprendizado e sua influência no desenvolvimento cognitivo da criança. Para isso, propôs dois níveis de desenvolvimento. O primeiro deles, chamou de nível de desenvolvimento real, no qual a criança é capaz de desenvolver determinadas tarefas de forma independente; suas funções mentais são resultado de ciclos de desenvolvimento já completados. O segundo nível é aquele em que a criança ainda não consegue concluir as tarefas por si mesma, necessitando de um suporte externo, seja material ou cultural. Este nível o autor chamou de nível de desenvolvimento potencial.

A grande contribuição de Vigotski foi, no entanto, identificar uma distância entre esses dois níveis, ou seja, entre aquilo que a criança pode fazer sozinha e aquilo que ela só consegue realizar com a ajuda de outro, denominando-a de zona de desenvolvimento proximal.

Ela é a distância entre o nível de desenvolvimento real, que se costuma determinar através da solução independente de problemas, e o nível de desenvolvimento potencial, determinado através da solução de problemas sob a orientação de um adulto ou em colaboração com companheiros mais capazes. (Vigotski, 2000a, p. 112)

É nesta zona que o aprendizado desempenha papel fundamental no desenvolvimento psicológico da criança. O aprendizado orientado somente para os níveis de desenvolvimento que já foram atingidos é ineficaz e insuficiente para o desenvolvimento global da criança.

A zona de desenvolvimento proximal define, assim, as funções mentais que ainda não amadureceram, mas estão em processo de maturação. Vigotski chamou tais funções de "brotos" ou "flores", mas não "frutos do desenvolvimento". O que é zona de desenvolvimento proximal hoje será o nível de desenvolvimento real amanhã e assim, prospectivamente. De acordo com esta perspectiva, "o bom aprendizado é aquele que se adianta ao desenvolvimento" (idem, ibid., p. 117). Nesta concepção, os processos de aprendizagem não coincidem com os de desenvolvimento e nem compõem com eles uma identidade única. $\mathrm{Na}$ realidade, os processos de desenvolvimento são mais lentos e progridem impulsionados pela aprendizagem.

O caminho que o indivíduo vai percorrer para desenvolver funções que estão latentes, ou seja, que ainda estão em processo de amadurecimento e que se tornarão funções consolidadas, pode sofrer interferência dos educadores. A partir do momento em que o professor 
percebe e atua na zona de desenvolvimento proximal, ele propicia a ampliação do nível de desenvolvimento real e contribui para movimentar os processos de desenvolvimento que ainda estão latentes nos membros mais imaturos da cultura. Ao interagir com novos conhecimentos, o ser humano se transforma. No ensaio vigotskiano, isso significa que os conceitos científicos apreendidos introduzem novos modos de operação intelectual acerca da realidade.

Alguns psicólogos do século passado, entretanto, demonstraram que uma pessoa só consegue imitar aquilo que está em seu nível de desenvolvimento potencial. Assim como a linguagem, a imitação e o aprendizado são funções especificamente humanas, pois "pressupõem uma natureza social específica e um processo através do qual as crianças penetram na vida intelectual daqueles que as cercam" (idem, ibid., p. 115).

Nesse sentido, vimos que Léo imitava as ações de Camila, construindo comportamentos relacionados à cultura escolar que ele desconhecia. Estes fatos nos mostram que é necessário haver espaços dentro do hospital onde as crianças possam interagir e trocar conhecimentos, trabalhando pedagogicamente as informações que lhes chegam. A pedagogia hospitalar deve criar e garantir esse espaço de aprendizagem (Fontes, 2005a).

\section{Cena III: os conhecimentos escolares...}

(C) Tia, Léo come duas marmitas na hora do almoço.

(P) Tu tomas conta, hein Camila? E você, come quantas marmitas?

(C) Muito mal uma, ne?

(P) Só uma? E Suzan?

(S) Um quarto de uma.

(P) Hi, Suzan, mas vai aumentar. Hoje você vai comer metade. Não é isso? Então, vai aprender com ele (referindo-se a Léo).

(C) Come o meio.

(P) Isso, Camila. Metade significa que vai comer até o meio da marmita.

(L) Comi duas quentinhas. 
Observa-se que alguns conhecimentos adquiridos na escola são apresentados espontaneamente pelas crianças diante da situação hospitalar. Quando Suzan disse comer 1/4 de uma marmita na hora do almoço e a professora-pesquisadora a incentivou a comer metade de uma, em função de sua doença, Camila logo respondeu que Suzan iria comer $1 / 2$ da marmita.

O aprendizado é, assim, uma das principais fontes de construção de conceitos da criança em idade escolar, embora a criança ainda não tenha consciência delas. Segundo Oliveira (1992, p. 33): "a intervenção pedagógica provoca avanços que não ocorreriam espontaneamente". O professor assume, então, o papel de agenciador de conhecimentos, mediando a troca e construção de conhecimentos no espaço hospitalar.

\section{Cena IV: os conhecimentos procedimentais...}

(P) Então está bem. O que vocês querem fazer... Vou dar...

Antes que eu concluísse meu raciocínio, Camila gritou:

(C) Tinta colorida!

(P) Tinta é complicado. Como é que você vai pintar com tinta se uma das mãos está presa?

Camila estava tomando medicação intravenosa em sua mão direita e reclamava de dores; locomovendo-se acompanhada de um tripé que suspendia o soro.

(C) Eu faço com a outra...

(P) Você faz com a outra? Deixe-me ver se tem tinta aqui. Tem que pegar aquele papel grande para colocar na mesa, não é isso?

(C e L) É...

Observamos neste episódio como as crianças criam estratégias para se adaptar às situações e não terem suas atividades interrompidas.

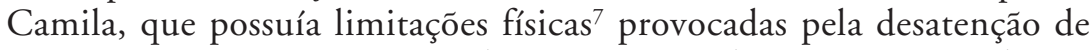
quem pôs o soro em sua mão direita sem perceber ser a criança destra, propôs à professora uma solução alternativa. Ela sugeriu a utilização da mão que estava livre para realizar a atividade de pintura, dizendo: Eu faço com a outra. 
A criança, sem o saber, utilizou-se de um saber procedimental (saber-fazer) que nem a professora-pesquisadora dominava. Esta passagem mostra a importância da linguagem como canal de mediação semiótica através do qual os homens, ao agirem sobre o meio, se comunicam e se constituem (Vigotski, 2000a e 2000b).

A fala é mais um instrumento por meio do qual a cultura é transmitida. A linguagem intercambia entre o social e o individual, modificando e construindo conhecimentos e sujeitos. Durante o processo de desenvolvimento, o indivíduo interage com outros e com o mundo que o cerca. A partir do momento em que o indivíduo internaliza a linguagem, ou seja, a partir do momento em que ele domina os códigos culturais e as teias de relaçóes presentes em seu grupo social, passa a utilizar a fala como instrumento de pensamento.

Vigotski (2000b, p. 156-157) afirma que "o pensamento não é simplesmente expresso em palavras, é por meio delas que ele passa a existir". Por trás das palavras, existe uma lógica independente do pensamento que ele expressa como a sintaxe dos significados das palavras.

Outro fato, também marcado pela linguagem, diz respeito ao uso do verbo querer utilizado nas falas das crianças ao longo da interação na sala de recreação. Quando a professora-pesquisadora perguntou o que as crianças queriam fazer e, antes mesmo que concluísse seu raciocínio, Camila gritou, numa explosão de alegria, mostrando seu desejo, sua vontade se impondo diante das adversidades do meio: Tinta colorida!

A próxima cena apresentará o papel da linguagem na construção dos desejos, na exposição de idéias e na organização do pensamento da criança.

Cena V: o papel da linguagem na construção do conhecimento...

Camila queria monopolizar todas as cores.

(P) Decide, qual cor você quer?

(C) Pode ser qualquer cor.

(P) Não, qualquer não. Você escolhe. Olha, tem seis cores.

(C) Seis?

(P) É. 
(C) Ah, é!

(P) Qual você quer?

Depois de pensar um pouco, Camila decidiu:

(C) Quero amarela.

Em outro momento...

(P) $\mathrm{O}$ médico falou pra você que você vai embora na semana que vem?

(C) Não... Ele falou assim: Até semana que vem, eu devo já te dar alta.

(P) Ah...tá...

(L) Aí eu vou pintar com essa tinta?

(P) É. Por que? Você quer outra? Eu só tenho essa. O que é que você quer? Você quer lápis de cor?

(L) É.

(C) Ele quer tinta de pintar parede...

(P) Não gente, a tinta de pintar parede é tinta para pintar parede e não papel. É isso que você quer Léo?

(P) É. Vocês já viram a moça que veio pintar a parede aqui?

(C) Eu vi.

(P) Sabiam que ela é artista? Ela é artista plástica.

(C) Eu já vi ela aqui. Eu já vi ela aqui.

(L) Eu vou pintar com essa tinta? (Referindo-se à tinta guache que estava sobre a mesa).

(P) É aqui, olha, no papel. Não vai pintar a parede, não.

(L) Como é que eu vou fazer com essa água?

Contagiado pela produção verde e amarela ao seu redor, Léo disse:

(L) Eu vou fazer o Brasil.

(P) Ah, vai fazer o Brasil? Ih, ela chegou! Foi liberada? Então, senta aqui. (Referindo-se a Jéssica, que havia saído para tomar um suco, segundo sua mãe).

(P) Olha, essa mão, Camila!

(L) Camila, por que você não chega a sua folha um pouquinho pra lá? 
(P) Você quer que eu pegue a outra mesa?' Tem aquela mesa ali, também!

(C) Eu quero ficar!

(P) Quer ficar lá?

(C) Eu quero a dos grandes. (Camila refere-se aos bancos, onde os adultos costumam sentar-se para ver a televisão, que também se encontra na sala de recreação).

(P) E você, Jéssica, o que quer fazer?

(J) Eu quero fazer... farinha colorida com isso daqui; olha?

A possibilidade de dialogar, de expor suas idéias contribui para que a criança resgate sua autonomia no ambiente hospitalar, bem como, através da linguagem, expresse sentimentos, organize idéias e ordene ações.

Vigotski (2000b) desenvolveu uma das mais originais e brilhantes discussóes sobre a linguagem, como suporte e expressão do pensamento humano, utilizando-se da analogia com o instrumento como ferramenta concreta do pensamento humano. Segundo ele, o material básico do pensamento é a palavra. Enquanto o instrumento é visto como um meio externo, o signo é concebido como um meio interno do desenvolvimento humano.

Vigotski trabalha com duas funções básicas da linguagem. A principal delas é a do intercâmbio social: é para se comunicar com seus semelhantes que o homem cria e utiliza os sistemas de linguagem. A segunda função da linguagem é a do pensamento generalizante, onde a linguagem ordena o real, agrupando todas as ocorrências de uma mesma classe de objetos, eventos, situações, sob uma mesma categoria conceitual.

É também através da linguagem que a criança, ao expressar seus desejos e rejeiçôes, constrói sua identidade. Ao incentivar o querer e a possibilidade de desejar nas crianças hospitalizadas, a professora-pesquisadora buscava, por meio de atividades de caráter pedagógico, resgatar a identidade de ser criança, com suas fantasias, desejos e ações, que, muitas vezes, é esquecida durante uma internação hospitalar (Fontes, 2005b).

Cena VI: o papel da linguagem na constituição da identidade de ser criança numa enfermaria pediátrica...

(E) Vem cá, Léo.

(L) Ah... não! 
(E) Vamos lá, botar o termômetro. Você já volta. Vem.

Léo grita, protestando.

(L) Tia, bota aqui.

(E) Não. Vem aqui.

(E) Você já volta... Rapidinho.

Léo começa a chorar baixinho.

(E) Ah... vai chorar? Você volta rápido.

E conduzido pela enfermeira, Léo levanta-se da cadeira e vai para a enfermaria.

(P) Suzan, você chegou quando?

(S) Sexta-feira.

(C) Pincel, tia. Cadê o pincel, tia? Agora eu quero o azul. Eu quero esse aqui. Fininho, porque eu vou fazer a branca. (Referindo-se à faixa branca da bandeira brasileira).

Neste momento, Camila se distraiu e começou a usar o braço pelo qual recebia medicação intravenosa.

(Ac) Cuidado com isso daí...

(P) Ah, não! Não usa esse braço não!

(C) É.

É possível observar a alta rotatividade das crianças na sala de recreação da enfermaria pediátrica. Do grupo de quatro crianças reunidas naquele espaço, duas foram convidadas a se retirar, durante a atividade, para fazer algum tipo de exame ou tomar medicação. Mas a interrupção das atividades, que eram prazerosas, não ocorria sem protestos.

(...) A formação de identidade se apresenta como um processo complexo pelo qual a criança começa a se posicionar como um indivíduo em oposição aos outros; a formação do Eu envolve a afirmação de uma identidade e uma expulsão do outro para fora dessa identidade. (Smolka, Góes \& Pino, 1998, p. 155)

A diferenciação é um conceito-chave na psicologia sócio-genética de Wallon. Nela, a distinção entre o eu e o outro só se adquire progressivamente, num processo que se faz nas e pelas interaçóes sociais. 
$\mathrm{Na}$ trajetória do desenvolvimento, Wallon admite a existência de duas fases alternantes: a centrípeta (a de predomínio afetivo) e a centrífuga (a de predomínio da inteligência). O recém-nascido seria, assim, centrípeto em tempo integral, ocupado primordialmente com seu eu e pouco reagindo aos estímulos do mundo físico. Com a mediação social, o bebê vai se tornando, aos poucos, um ser centrífugo, quando os movimentos impulsivos ganham a conotação de expressivos, voltados para o outro ao seu redor. Aos seis meses, a presença do outro é o fator mais estimulante. O sentido do processo de socialização é de crescente individuação.

A construção do eu corporal é condição básica para a construção do eu psíquico, tarefa central no estágio que Wallon chamou de personalista. Porém, depois de sair da imersão do mundo físico e antes de adquirir a consciência de si, a criança, então, encontra-se imersa num estado de sociabilidade sincrética, não distinguindo entre a sua personalidade e a do outro (novamente centrípeta). A grande virada vem por volta dos três anos de idade, quando a criança começa a empregar o pronome pessoal "eu". A criança opõe-se, então, ao que distingue como sendo diferente dela, o não-eu. Utilizando-se de uma expressão de Pierre Janet, Wallon (1975, p. 159) nos dirá que, "no seu esforço para se individualizar, o eu não pode agir de outra maneira senão opondo-se à sociedade na sua forma primitiva", uma vez que o indivíduo é geneticamente um ser social.

$\mathrm{Na}$ teoria de Wallon, essa relação entre o eu e o não-eu, ou seja, o outro, não se dá de forma harmoniosa. Ela se efetua por um tipo especial de interação que é a negação do outro. É pela expulsão do que é alheio de dentro de si que se fabrica o eu. O processo que começou pela simbiose tem no horizonte a individuação. A simbiose fetal, prolongada pela simbiose alimentar e afetiva, precisa ser interrompida para dar lugar a uma individualidade diferenciada, causando o conflito.

Para Wallon (1971, 1975), a constituição da individualidade passa por atitudes de oposição ao outro. Nos momentos de passagem de um estágio a outro, uma crise pode gerar conflitos na relaçẫo do indivíduo com o outro ou consigo mesmo. Nesta teoria, os conflitos, aos quais Wallon chama de fatores dinamogênicos, são vistos como propulsores do desenvolvimento humano. Nesse embate de forças, a criança procura afirmar-se expulsando a representação do outro, ou seja, o não-eu de dentro de si, num exercício de diferenciação. 
Com ênfase no aspecto social da constituição do eu, Wallon (1975, p. 159) afirma que "o outro é um parceiro perpétuo do eu na vida psíquica”. Mesmo na vida adulta, ainda é muito tênue a fronteira que separa o eu do outro, podendo desfazer-se, momentaneamente, devido à situação específica de cansaço ou dificuldade de alguma ordem.

Foi contestando a autoridade da enfermeira, que ameaçava sua autonomia, que Léo procurou afirmar sua individualidade, ainda que por pouco tempo. Léo criou estratégias para não interromper sua atividade, o que poderia ter sido feito se houvesse alguma flexibilidade na ação da enfermagem. Embora não fosse a maioria, alguns profissionais da equipe de saúde do hospital ainda não compreendiam a importância daquele momento de recreação para a criança hospitalizada. Sentir prazer na realização de uma atividade contribui para o bem estar da criança enferma e atua no restabelecimento de sua saúde, assim afirmam Taam (2000) e Fontes (2003).

A atividade que Léo desenvolvia parecia lhe dar prazer, pois, quando foi interrompido, ele ameaçou chorar e saiu sob protestos da sala de recreação. Para Wallon (1971, p. 47), "Os gritos são uma reação emocional de origem extereoceptiva voltada para uma ação exterior".

Dantas (1992) nos fala que a emoção é descrita, no sentido geral, como anárquica e explosiva, imprevisível e, portanto, assustadora. Talvez seja esse o motivo pelo qual é tão raramente refletida pelas teorias pedagógicas.

$\mathrm{Na}$ interação entre adultos e crianças, cuja temperatura emocional é mais elevada, os resultados daquele 'circuito perverso' fazem-se sentir freqüentemente. Tão raramente tematizada, esta questão passa assim para o primeiro plano: a educação da emoção deve ser incluída entre os propósitos da ação pedagógica, o que supõe o conhecimento íntimo do seu modo de funcionamento. (Dantas, 1992, p. 89)

A atividade emocional é uma das mais complexas características do ser humano, pois ela é simultaneamente biológica e social. É através dela que se realiza a transição do biológico ao cognitivo por meio da interação sócio-cultural. Sua natureza contraditória surge do fato de participar de dois mundos - o biológico e o social -, além de fazer a transição entre eles na dimensão psicológica da constituição do sujeito (Wallon, 1941). 
A hospitalização é uma situação que altera a rotina da criança e sua família. É natural a criança apresentar uma fragilidade emocional que pode prejudicar a sua compreensão do real. Por isso, refletir sobre as causas que estão na origem da emoção é uma das funções da educação no hospital.

Com exceção de recursos físicos, (...) o método mais adequado para reduzir [a emoção] é opor-lhe a atividade perceptiva ou intelectual. Todo aquele que observa, reflete ou mesmo imagina, abole em si o distúrbio emocional. (Wallon, 1971, p. 79)

Embora a emoção traga consigo a tendência de reduzir a eficácia cognitiva do sujeito, a qualidade final do comportamento que dela se origina dependerá da capacidade do sujeito de retomar o controle da situação. Nesse sentido, a interação social poderá ser bem-sucedida e soluçōes inteligentes poderão ser mais facilmente encontradas.

A sensibilidade possui, assim, dois níveis: um afetivo e outro cognitivo. A meta educacional é, atuando no cognitivo, alcançar o afetivo e proporcionar ao sujeito não somente a construção de seu conhecimento, mas, através dele, sua própria constituição. Isso significa que a inteligência para evoluir depende, desde os primeiros meses de vida do ser humano, das conquistas realizadas no plano da afetividade e, dialeticamente, a afetividade para evoluir depende, ao longo de toda a vida, das conquistas realizadas no plano da inteligência.

Ao tomar como foco de análise as constatações empíricas apresentadas no episódio narrado, podemos inferir que a oposição da criança aos procedimentos da rotina hospitalar, muitas vezes invasivos e dolorosos, parece ser salutar para a constituição de sua identidade que é única e intransferível e, portanto, precisa ser respeitada.

Destacamos que, quando as crianças eram convidadas a se retirar da atividade na sala de recreação para fazer exames, elas deixavam de ser crianças e voltavam a ser pacientes. Dessa forma, seus desejos eram pouco considerados. $\mathrm{Na}$ fala das crianças, a sala de recreação apareceu como espaço seguro, como uma referência ao prazer, a um lugar protegido, onde se pode brincar.

(P) Vocês gostam de vir pra cá, pra salinha? Por quê?

(L) Pra brincar. 
Cena VII: a brincadeira como reelaboração de conhecimentos no hospital...

A primeira imagem que se tem de Camila é brincando de casinha com a boneca Barbie e seu kit junto a Jéssica. Aproximei-me para observar melhor a interação das duas.

(C) $\mathrm{Hi}$, a tia chegou.

(P) O que vocês estão fazendo?

(C) Brincando de casinha.

(P) Mas a casinha não é de vocês. É da Barbie.

(C) Mas a gente é ela.

Cada menina tinha uma Barbie. Todas as bonecas eram da sala de recreação.

(P) E quem é o Bob?

(J) Bob é o namorado da Barbie.

(C) É.

(P) De qual Barbie?

(C) De todas.

(J) Bibibibibibi... Vamos meu amor.

(P) Que chique! Um carro conversível vermelho! Para onde Bob vai levar a Barbie?

(C) Ué, pra casa.

O que significa brincar de casinha (expressão clássica do vocabulário infantil) numa enfermaria pediátrica? O recorte desta breve cena é para mostrar que, quando as crianças brincam, elas criam um mundo imaginário seguro capaz de re-elaborar uma realidade que lhe é dolorosa, tornando-a compreensível e, dentro do possível, prazerosa. A brincadeira propicia a aproximação de pares. Note-se que, nesta cena, as crianças eram todas meninas. As interações fluíam espontaneamente, sem a intervenção de um adulto, e davam suporte à troca de conhecimentos durante a brincadeira.

A brincadeira também pode ser lida, neste caso, como uma rota de fuga de uma realidade que não pode ser suportada como ela é. Mais 
comunicativa, Camila dominava com segurança o cenário das brincadeiras. Talvez em outras interaçóes de brincadeiras, o tema doença tivesse aparecido. Mas, naquele momento, as crianças encarnavam a fantasia de ser a própria Barbie, bela, elegante, rica, feliz e voltando para casa. Através dos jogos de imaginação, a criança projeta seus desejos irrealizáveis: "Liga-se aos seres que para ela têm maior prestígio, aos que têm importância para os seus sentimentos, aos que exercem um atrativo (...). Mas, ao mesmo tempo, ela própria torna-se nessas personagens" (Wallon, 1941, p. 76).

Embora pareça apenas prazeroso, o brinquedo é uma reelaboração das frustraçõos causadas pelos desejos não satisfeitos da criança. Talvez em função disso, possamos compreender os motivos das diversas referências que a criança hospitalizada faz de sua casa e da escola (quando já estuda), seja através de desenhos ou brincando de casinha.

Podemos observar ainda que, embora todos os objetos mencionados na brincadeira tivessem uma base material (as três bonecas, suas roupas, o boneco e o carro), a casa era o único significado utilizado sem referência no plano material, ganhando status autônomo em relação à realidade, mas significativo no imaginário infantil, porque mentalmente a criança vê o objeto por trás da palavra (Vigotski, 2000b).

É no brinquedo e no faz-de-conta que a criança pode realizar uma variedade de ações que estão muito além de seus limites de compreensão e de suas próprias capacidades. $\mathrm{O}$ brinquedo surge juntamente com a capacidade da criança de imaginar, de transcender o real e construir um mundo simbolicamente possível. O brinquedo, na realidade, surge da necessidade e do desejo frustrado da criança em realizar algo que concretamente ela não pode naquele momento. Esse mundo de desejos realizáveis, que desencadeia um novo comportamento na criança, é o que chamamos de brinquedo.

Todavia, embora pareça uma atividade puramente prazerosa, o brinquedo age como uma reelaboração das frustrações de tendências não satisfeitas e está cercado por regras que a criança constrói a partir de seu meio social. "O que na vida real passa despercebido pela criança torna-se uma regra de comportamento no brinquedo" (Vigotski, 2000a, p. 125).

Brincadeira e jogo assumem significados muito próximos nos estudos de Vigotski. Primeiro, porque ambos são guiados por regras e, segundo, porque nascem de uma situação imaginária. Em níveis mais elevados do desenvolvimento das funçôes mentais superiores, o homem 
transforma a brincadeira (com regras ocultas e situação imaginária evidente) em jogos (com regras claras e situação imaginária oculta). Ao atuar num nível de desenvolvimento que não é o seu, encenando um comportamento adulto e usando uma linguagem que não é a sua, a criança cria e atua em sua própria zona de desenvolvimento proximal, re-elaborando internamente (psíquica e afetivamente) o que capta do meio externo.

O papel equivalente dado ao brinquedo e ao ensino-aprendizagem na criação da Zona Proximal de Desenvolvimento é coerente com a preocupação teórica central de Vygotsky, que é a de enfatizar a importância do contexto histórico-cultural na formação das estruturas psicológicas superiores da pessoa. (Vasconcellos, 1998, p. 53-4)

Vigotski (2000b) ressaltou a enorme influência que o brinquedo exerce no desenvolvimento da criança. É através do brinquedo que a criança aprende a agir numa esfera cognitiva descolada da realidade imediata e passa a dominar os objetos independentemente daquilo que vê, contextualizando-os e ressignificando-os.

O significado do brinquedo também foi uma categoria investigada por Vigotski. Se, em princípio, o significado subordina-se ao objeto, quando a criança constrói sua brincadeira, a relação se inverte e o objeto fica subordinado ao significado. Vigotski exemplifica com a transformação do cabo de vassoura em cavalo de pau. Embora a criança ainda não seja capaz de imaginar um cavalo sem qualquer referência a um suporte concreto, ela já consegue separar o significado (um cavalo imaginário) de seu objeto concreto (um cavalo real).

No brinquedo, a criança opera com significados desligados dos objetos e ações aos quais estão vinculados no mundo real. Do mesmo modo, ao transferir significados de um objeto para outro, a criança não consegue distinguir a palavra da propriedade do objeto que ela nomeia, a palavra é parte inerente ao objeto que designa. Ou seja, ela vê mentalmente o objeto por trás da palavra. $\mathrm{O}$ mesmo pode ser dito em relação à ação: quando a criança significa sua ação, esta deixa de ter uma existência real e passa a ser incorporada dentro do contexto da brincadeira.

Em um sentido, no brinquedo a criança é livre para determinar suas próprias ações. No entanto, em outro sentido, é uma liberdade ilusória, pois suas ações são, de fato, subordinadas aos significados dos objetos e a criança age de acordo com eles. (Vigotski, 2000a, p. 136) 
Para Vigotski, o brinquedo não é o aspecto predominante da infância, mas é, sem dúvida, um dos fatores mais importantes do seu desenvolvimento. Segundo ele, é através do brinquedo que a criança aprende a respeitar regras e a controlar seu próprio comportamento que, fora desta situação imaginária, seria impossível dela compreender. O brinquedo dá início a uma série de mudanças no desenvolvimento interno da criança, ao criar uma zona de desenvolvimento proximal que a leva a comportar-se além do habitual de sua idade, tanto cognitiva quanto afetivamente.

$\mathrm{Na}$ idade escolar, o brinquedo não desaparece, mas permeia a relação da criança com a realidade. $\mathrm{O}$ brinquedo tem assim sua continuação interior e se manifesta no jogo de significados da instrução escolar e no trabalho cerceado por regras, ou seja, o brinquedo se perpetua nas situações imaginárias criadas pelos jogos de linguagem. Enfim, o brincar é um direito, não um favor que concedemos ou não às crianças hospitalizadas. Era brincando que Camila, Jéssica e outras crianças re-elaboravam sua vivência no hospital, compreendiam melhor a situação de hospitalização e se tornavam mais saudáveis.

\section{Considerações finais}

O texto procurou demonstrar as diferentes dimensões que o trabalho pedagógico pode assumir junto a crianças hospitalizadas. Valendo-se dos estudos de Wallon e Vigotski, procurou analisar, mediante a importância que as relaçôes sociais assumem no contexto hospitalar, as possibilidades de interlocução entre a educação e a saúde.

É através da relação interpessoal concreta que a criança constrói sua subjetividade. Portanto, a interação social, seja diretamente com outros membros da cultura, seja por meio dos diversos elementos do ambiente culturalmente estruturado, fornece a matéria-prima para o desenvolvimento psicológico do indivíduo. Vimos que, mesmo hospitalizada, a criança continua interagindo com o meio, aprendendo e se desenvolvendo.

A pedagogia hospitalar deve favorecer e estimular este processo, dando oportunidade à criança para dizer sua palavra. A fala, como canal de expressão e instrumento de constituição do pensamento, deve ser estimulada através de atividades pedagógicas em que a criança tenha oportunidade de se expressar livremente. Ao dialogar, a criança expõe dúvidas, 
medos, ansiedades e organiza seus pensamentos. Demonstra sua compreensão do real e até que ponto as emoções embaçam sua visão da realidade. Refletir sobre as origens dos estados emocionais também é uma das dimensões da ação pedagógica no hospital. Ao levar a criança a refletir sobre as causas de seu desconforto emocional, a educação contribui não somente para que o sujeito retome o controle da situação, como também favorece seu autoconhecimento. Outrossim, o ato de aprender resgata o sentimento de auto-estima na criança, fortalecendo seus desejos e ações diante dos procedimentos invasivos e dolorosos de um tratamento médico. Nesse sentido, a idéia de "escola", ao lado da brincadeira, surge como uma importante referência à infância no contexto hospitalar, pois, ao aprender brincando, as crianças resgatam a vivência de infância que foram obrigadas a abandonar, mesmo que temporariamente, em função da doença.

Por fim, as lições de Camila, Léo, Jéssica e Suzan expressam a alegria de aprender e de viver, apesar da hospitalização. O papel da educação é, assim, o de estimular esta aprendizagem que impulsiona o desenvolvimento humano, tornando o ambiente hospitalar menos hostil.

\section{Recebido em abril de 2007 e aprovado em outubro de 2007.}

\section{Notas}

1. A sala de recreação era um espaço localizado ao lado da enfermaria pediátrica, separado desta por uma divisória, com três mesas e cadeiras de mobiliário de Educação Infantil, um armário e dois bancos de madeira, uma estante de aço e um televisor. Ali, além das atividades pedagógicas, aconteciam as refeições e pais e crianças se reuniam para assistir televisão, brincar ou jogar videogame.

2. As crianças na enfermaria pediátrica ficavam acompanhadas por seus responsáveis.

3. Todos os nomes são fictícios para proteger a identidade dos sujeitos.

4. Suzan era uma adolescente de 16 anos que estava internada com suspeita de anorexia.

5. A anorexia é uma doença que se configura pela falta de apetite com acentuada perda de peso e outros sintomas resultantes de conflito emocional. (Cf. Bueno, 1986, p.101). "A anorexia mental surge freqüentemente próximo à puberdade ou à adolescência em meninas. (...) As restrições alimentares podem começar em decorrência de um choque emocional ou de conflitos psicológicos evidentes, embora, quase sempre, elas se instalem de maneira progressiva sem causa aparente. (...) A jovem lastima-se por estar engordando, o que enseja a implantação de um regime de emagrecimento. (...) A síndrome psíquica acompanha-se de uma síndrome somática, caracterizada por emagrecimento considerável, sendo que algumas anoréticas perdem até a metade do seu peso. $\mathrm{O}$ emagrecimento afeta todo o 
O papel da educação no hospital: uma reflexão com base nos estudos de Wallon e Vigotski

corpo; o rosto fica pálido, os olhos e as faces tornam-se vazios, surgem rugas, os seios murcham; as jovens parecem velhas" (Ajuriaguerra, 1980, p. 185-186).

6. O nome da escola também é fictício para proteger a identidade de Jéssica.

7. Camila recebia medicação intravenosa através de uma seringa injetada na superfície de sua mão direita.

\section{Referências bibliográficas}

AJURIAGUERRA, J. Manual de psiquiatria infantil. Rio de Janeiro: Masson do Brasil, 1980.

BUENO, F.S. Dicionário escolar da lingua portuguesa. Rio de Janeiro: MEC/FAE, 1986.

DANTAS, H. A afetividade e a construção do sujeito na psicogenética de Wallon. In: De la Taille, Y.; Oliveira, M.K.; Dantas, H. Piaget, Vygotsky e Wallon: teorias psicogenéticas em discussão. São Paulo: Summus, 1992. p. 85-98.

FONTES, R.S. A escuta pedagógica à criança hospitalizada: discutindo o papel da educação no hospital. 2003. 205f. Dissertação (Mestrado) - Faculdade de Educação, Universidade Federal Fluminense, Niterói.

FONTES, R.S. A escuta pedagógica à criança hospitalizada: discutindo o papel da educação no hospital. Revista Brasileira de Educação, Rio de Janeiro, n. 29, p. 119-138, maio/ago. 2005a. Disponível em: <http://www.anped.org.br>. Acesso em: 22 jan. 2007.

FONTES, R.S. O desafio da educação no hospital. Presença Pedagógica, Belo Horizonte, v. 11, n. 64, p. 21-29, jul./ago. 2005 b.

OLIVEIRA, M.K. Vygotsky e o processo de formação de conceitos. In: De la Taille, Y.; Oliveira, M.K.; Dantas, H. Piaget, Vygotsky e Wallon: teorias psicogenéticas em discussão. São Paulo: Summus, 1992. p. 23-34.

SMOLKA, A.L.B.; GÓES, M.C.R.; PINO, A. A constituição do sujeito: uma questão recorrente? In: Wertsch, J.; Del Rio, P.; Alvarez, A. Estudos socioculturais da mente. Porto Alegre: ARTMED, 1998. p. 143-158.

TAAM, R. Assistência pedagógica à criança hospitalizada. 2000. $216 \mathrm{f}$. 
Tese (Doutorado) - Faculdade de Educação, Universidade Federal Fluminense, Niterói.

VASCONCELLOS, V.M.R.V. Zona de desenvolvimento proximal: a brincadeira na creche. In: Freitas, M.T.A. (Org.). Vygotsky: um século depois. Juiz de Fora: EDUfJF, 1998. p. 47-72.

VASCONCELLOS, V.M.R.V. Construção da subjetividade: processo de inserção de crianças pequenas e suas famílias à creche. 2002. $185 f$. Tese (Concurso Público para professor titular em Educação Infantil) - Faculdade de Educação, Universidade do Estado do Rio de Janeiro, Rio de Janeiro.

VIGOTSKI, L.S. A formação social da mente. São Paulo: Martins Fontes, 2000a.

VIGOTSKI, L.S. Pensamento e linguagem. São Paulo: Martins Fontes, $2000 \mathrm{~b}$.

WALLON, H. A evolução psicológica da criança. Rio de Janeiro: Andes, 1941.

WALLON, H. As origens do caráter na criança: os prelúdios do sentimento de personalidade. São Paulo: DIfEL, 1971.

WALLON, H. Psicologia e educação da infância. Lisboa: Estampa, 1975. 